\title{
Saúde pública e pós-democracia: do Estado Democrático de Direito ao Estado Pós- Democrático
}

\author{
Public health and post-democracy: from the Democratic State of Law \\ to the Post-Democratic State
}

Rubens Casara'

DOI: 10.1590/0103-110420185303

\section{Introdução}

Ao se falar em Estado Democrático de Direito, por evidente, evoca-se, em termos weberianos, um 'tipo ideal' de Estado que tem como principal característica a existência de limites legais ao exercício do poder. Na realidade, o Estado concreto, para além dos idealismos, mesmo que aposte na lei e no direito para evitar abusos, convive sempre com uma margem de ilegalidade produzida por particulares e, principalmente, pelo próprio Estado. Isso porque, ao contrário do que muitos sustentam, é o poder político que estabelece e condiciona o direito. Condicionado, o direito acaba afastado, sempre que necessário, à realização do poder, de qualquer poder. Há manifestações de poder que escapam da legalidade, porque ao longo da história, e Marx já havia percebido isso, a legalidade esteve (quase) sempre a serviço do poder; e sua função se limitava a legitimar 'a lei do mais forte'.

O que há de novo não é a violação dos limites ao exercício do poder. Em razão da mercantilização do mundo, da sociedade do espetáculo, do despotismo do mercado, do narcisismo extremo, da reaproximação entre o poder político e o poder econômico, do crescimento do pensamento autoritário, perdeu-se qualquer pretensão de fazer valer esses limites, que hoje existem apenas como um simulacro, como um totem que faz lembrar conquistas civilizatórias que já existiram, mas que, na atualidade, não passam de lembranças que confortam. Mais do que a violação de limites, o que caracteriza a chamada pós-modernidade é a total desconsideração, ou mesmo a ausência, dos limites, que um dia foram pensados, ao poder.

Por 'pós-democrático"1, entende-se um Estado sem limites rígidos ao exercício do poder, isso em um momento em que o poder econômico e o poder político se aproximam, e quase voltam a se identificar, sem pudor. O ganho democrático que se deu com o Estado moderno, nascido da separação entre o poder político e o poder econômico, desaparece na pós-demo-

1 Fundação Oswaldo Cruz (Fiocruz), Escola Nacional de Saúde Pública Sergio Arouca (Ensp) - Rio de Janeiro (RJ), Brasil. Orcid: https://orcid org/0000-0002-14193718

rubens.casara@gmail.com cracia; e, nesse particular, pode-se falar em uma espécie de regressão pré-moderna. Está em vigência uma espécie de absolutismo de mercado.

Pós-democrático, para dar nome à hipótese de que o Estado Democrático de Direito foi superado por um Estado sem limites ao exercício do poder, vai ao encontro da tese de que o neoliberalismo está levando à era da pós-democracia². De fato, o 'pós-democrático' é o Estado compatível com o neoliberalismo, com a transformação de tudo em mercadoria. Um Estado 
que, para atender ao ultraliberalismo econômico, necessita assumir a feição de um Estado Penal, de um Estado cada vez mais forte e voltado à consecução dos fins desejados pelos detentores do poder econômico. Fins que levam à exclusão social de grande parcela da sociedade, ao aumento da violência (não só da violência física, que cresce de forma avassaladora, como também da violência estrutural, produzida pelo próprio funcionamento 'normal' do Estado pós-democrático), à inviabilidade da agricultura familiar, à destruição da natureza e ao caos urbano, mas que necessitam do Estado para serem defendidos e legitimados.

Não há, ao contrário do que sustentam os discursos de viés liberal dos que estão satisfeitos com o Estado Pós-Democrático, a diminuição da intervenção estatal na vida da sociedade. Ao contrário, o Estado PósDemocrático revela-se um Estado forte e, possivelmente, o Estado menos sujeito a controle desde a criação do Estado Moderno. Na pós-democracia, o político torna-se, como desejava Carl Schmitt em 1932, o mero espaço da dicotomia amigo e inimigo. Essa diferenciação política tem a função de caracterizar o extremo grau de intensidade da adesão e funcionalidade à razão neoliberal. No Estado Pós-Democrático, a diferenciação exclusivamente política, já que desaparecem as funções que constituíam o 'braço esquerdo' do Estado (tais como as políticas inclusivas e de redução da desigualdade), é a diferenciação entre 'amigo' do mercado e 'inimigo' do mercado, este último será o indivíduo indesejável sobre o qual recairá o poder penal.

Em apertada síntese, pode-se afirmar que o estado capitalista, para sobreviver, exigiu, em diferentes quadras históricas, o Estado Liberal de Direito, o Estado Social de Direito, o Estado Fascista, o Estado Democrático de Direito e, agora, o Estado Pós-Democrático. Para tornar-se hegemônico e superar definitivamente o Estado Absolutista, o projeto capitalista exigiu um Estado regulado por leis, em que prevalecia a ideia de separação entre o Estado e a sociedade civil (a sociedade civil, locus da atividade mercantil, espaço ved ado para o Estado), no qual a propriedade e a liberdade (entendida como liberdade para adquirir e possuir sem entraves, liberdade originária de onde derivariam todas as outras liberdades) eram compreendidos como os dois principais direitos fundamentais do indivíduo e no qual o significante 'democrático' aparecia para frisar a oposição em relação ao princípio monárquico do Estado absolutista. Com o agravamento da situação econômica de grande parcela da população, o aprofundamento dos conflitos sociais e a ameaça corporificada nas experiências socialistas, somados à perda da confiança no funcionamento concreto da 'mão invisível' e das 'leis naturais' do mercado, o Estado de Direito Liberal foi gradualmente substituído por um Estado Social de Direito que nasce como uma solução de compromisso entre os defensores do status quo e os que lutavam por transformações sociais (têm razão os que apontam o efeito mistificador e ideológico do Estado Social, que se revelou capaz de frear os ímpetos dos movimentos revolucionários e os protestos das classes não capitalistas). Como afirma Avelãs Nunes, tratou-se da primeira tentativa de substituir a 'mão invisível' da economia pela mão invisível do direito. No modelo do Estado Social de Direito, em que se percebe uma certa prevalência do político sobre o econômico, o Estado assume a função de realizar a 'justiça social', assegurar o pleno desenvolvimento de cada um e concretizar o projeto de vida digna para todos (princípio da dignidade da pessoa humana). Porém, em um quadro de crise econômica profunda, no qual a debilidade da economia nos países capitalistas não permitia minimamente a realização das promessas do Estado Social, com os detentores do poder econômico sedentos por aumentar os seus lucros, o projeto capitalista teve que assumir a forma de um Estado Fascista, antidemocrático e antissocialista, que apostava em resposta de força para manter a ordem e resolver os 
mais variados problemas sociais, na medida em que incentivava a ausência de reflexão. $\mathrm{O}$ Estado Fascista era um estado de direito, mas o direito fascista não representava um limite ao arbítrio e à opressão. Com a derrota política e militar dos Estados Fascistas, o projeto capitalista retoma a aposta em um modelo de Estado marcado pela existência de limites ao exercício do poder, dentre os quais destacam-se os direitos fundamentais. A aposta, porém, revelou-se equivocada, na medida em que os direitos fundamentais passaram a constituir obstáculos inclusive ao poder econômico. Com isso, a razão neoliberal, nova forma de governabilidade das economias e das sociedades baseada na generalização do mercado e na liberdade irrestrita do capital, levou ao Estado Pós-Democrático de Direito.

\section{Direito à saúde: de direito fundamental à mercadoria}

Os direitos humanos tornaram-se a linguagem hegemônica da dignidade humana. Aplausos e discursos em defesa dos direitos humanos não faltam. Todavia, como percebeu Boaventura de Souza Santos ${ }^{3}$, essa hegemonia no campo discursivo convive com fato assustador: grande parte da população mundial não alcançou a condição de sujeito de direitos humanos. Para muitos, reserva-se às pessoas a condição de não sujeitos, submetidos às várias formas de violência (física, moral, estrutural, simbólica etc.). Em outras palavras, se todos figuram como objetos dos discursos sobre direitos humanos, poucas pessoas têm reconhecidos e concretizados esses direitos.

Existem diversas concepções e teorias que procuram dar conta do conceito de direitos humanos. A dificuldade de encontrar um conceito adequado aumenta ao perceber que a maioria das concepções de direitos humanos são produtos da modernidade ocidental (poder-se-ia dizer: obra do homem branco europeu), um modo de ver e atuar no mundo que se caracterizou por reduzir o conhecimento à ciência, a política ao Estado e o direito à lei. Não se pode esquecer também que a modernidade ocidental, esse universo de relações de dominação sob a hegemonia eurocentrada, levou também à racionalidade neoliberal que transforma tudo e todos, inclusive o humano, em mercadoria, em objetos negociáveis.

Para muitos, os direitos humanos não passam de uma espécie de ideologia, uma representação ideológica capaz de mistificar a condição humana e tranquilizar as almas daqueles que, por ação ou omissão, são responsáveis pela violência contra as pessoas. Assim, o discurso dos direitos humanos, percebidos como abstrações, acabaria por esconder as violações concretas aos interesses e às necessidades de cada pessoa. Nesse sentido, pode-se afirmar que as concepções 'abstratas' dos direitos humanos produzem efeitos perversos ${ }^{4}$ que se relevam conexos e integrados: a) efeito ilusório, que dificulta a percepção da distância entre o discurso e a prática, ou melhor, entre os direitos previstos e os direitos efetivados (a previsão legal de um direito passa a funcionar como substituto de sua concretização); b) efeito imobilizador, uma vez que o reconhecimento legal do direito gera uma sensação de satisfação e de suficiência, de que não há mais o que se conquistar (eventuais violações dos direitos humanos seriam meras disfunções atribuíveis a erros individuais) e que, agora, cabe ao aparato estatal concretizar os direitos humanos; c) efeito de ordem, que reduz os direitos humanos àqueles consagrados na legislação nos termos em que são reconhecidos pelas Agências Estatais (em especial, o Poder Judiciário), o que faz com que se aceite que o aparato estatal possa selecionar, identificar, limitar, excepcionar, relativizar e conter os direitos humanos em nome da manutenção da ordem; d) efeito de legitimação de uma ordem hegemônica, uma vez que a compreensão dos direitos humanos está condicionada por uma determinada configuração de poder (não raro o significante 'direitos humanos' é utilizado para atacar projetos de 
poder alternativos, mesmo por governos que violam cotidianamente direitos de parcela de sua população) etc.

Fácil, pois, perceber a tensão entre o que 'é' (plano do 'ser') e o que deve ser (plano do 'dever ser'), bem como a diferença entre 'o que deve ser segundo o direito que é' e 'o que é no mundo-da-vida'. Por fim, 'o que é' está longe de se identificar com o que deveria ser em um mundo no qual os direitos humanos, reconstruídos para além do referencial do 'homem branco europeu', fossem respeitados.

Diante desse quadro, ainda com Boaventura de Souza Santos, não há como deixar de 'suspeitar' dos direitos humanos. Como a ideia de direitos humanos pode conviver com uma realidade que nega a grande parcela da população mundial as condições necessárias à vida minimamente digna? A que direitos se refere, e a quem pretendem proteger, os defensores dos direitos humanos?

Ao se falar em direitos humanos, recorre-se a dois significantes: direitos e humanos. Trata-se de um conceito complexo, portanto, uma vez que integrado por dois elementos vinculados entre si, em uma relação de complementariedade e, ao mesmo tempo, de contradição. Segundo Alessandro Baratta ${ }^{5(334)}$, há complementariedade,

no sentido de que pertence ao homem enquanto tal, segundo o direito; contradição no sentido de que o direito não reconhece ao homem o que lhe pertence enquanto tal.

Em outras palavras, ao longo da história, o direito não reconheceu à pessoa o que é necessário à sua plena realização; 'humano' e 'direito' são definidos do ponto de vista ideal em reciprocidade, enquanto no mundo-da-vida a pessoa concreta sofre a negação do direito a uma vida digna. Não raro, a legislação (o ‘direito’ reduzido à lei e à interpretação dada à lei) se coloca em oposição aos valores dos direitos humanos, em especial no que toca a vários segmentos étnicos e sociais subalternizados e excluídos das políticas sociais (basta lembrar de como o sistema de justiça brasileiro e seus atores tratam daqueles indesejáveis ao projeto neoliberal de acumulação ilimitada do capital6).

Chamam-se 'direitos humanos' aos direitos que pertencem a todas as pessoas naturais pelo simples fato de terem nascido. A pessoa o é por ter sido lançada na linguagem. É possível afirmar a existência de direitos (fenômeno que importa comunicação) porque a humanidade é composta de entes que têm seu mundo ao modo do que é falado, entes dotados de linguagem e em comunicação. Direitos humanos referem-se à realização plena da humanidade e englobam todos os direitos necessários à concretização da dignidade humana. Por essa razão, os direitos humanos devem ser apreciados a partir de uma análise conglobante. São, portanto, direitos compartilhados por todos, por todas as singularidades, enquanto pessoas naturais.

Os direitos humanos são apontados como direitos universais, posto que deveriam pertencer a todas as pessoas naturais, sem qualquer exceção, a todos os seres humanos. Tanto a Declaração de Independência dos Estados Unidos da América (1776) quanto a Declaração dos Direitos do Homem e do Cidadão (1789) destacam-se pela universalidade das afirmações feitas: 'todos os homens são criados iguais, dotados pelo seu Criador de certos Direitos inalienáveis', 'todos os homens', 'homens', 'todos os cidadãos', 'cada cidadão' etc. Assim, pretendia-se afastar qualquer dúvida acerca da intenção de que toda pessoa era titular desses direitos pelo simples fato de ter nascido, o que, em concreto, era negado pelos fenômenos da escravidão e do patriarcado. Na Constituição Brasileira de 1988, os direitos humanos, que tantas vezes são violados, encontram-se positivados como direitos fundamentais, entre os quais, o direito à vida, à integridade física e mental, à liberdade de expressão e de pensamento, ao meio ambiente, ao trabalho digno e à saúde.

A afirmada 'universalidade' dos direitos humanos merece problematização. Basta 
lembrar que Olympe de Gouges foi guilhotinada após publicar a Declaração dos Direitos da Mulher e da cidadã justamente para questionar a precária universalidade da declaração francesa. Há uma tensão inafastável entre o universal (aquilo que se pode afirmar como válido independentemente dos contextos) e o fundacional (o que representa uma identidade especifica, com memória, tradição, história e raízes). Basta pesquisar a situação dos direitos humanos em diversas regiões do mundo (ou até em regiões de um mesmo país) para chegar à conclusão de que inexiste, em concreto, um tratamento homogêneo ou mesmo validade universal de direitos em contextos políticos, econômicos ou culturais diversos.

Em países lançados em uma tradição autoritária, os direitos humanos são percebidos como obstáculos à eficiência repressiva do Estado (em regra, em favor do mercado), enquanto em regiões que foram capazes de construir uma cultura democrática, os direitos humanos funcionam como condição de legitimidade do Estado ou como condição de possibilidade da própria democracia. Não por acaso, há quem sustente que a dimensão material (substancial) da democracia corresponde à concretização dos direitos fundamentais, ou seja, dos direitos humanos reconhecidos pelos ordenamentos jurídicos.

Em relação aos direitos humanos, não se pode ignorar que uma determinada cultura (situada, pois, no plano fundacional) passou a se afirmar como universal. $O$ que se entende hoje por 'direitos humanos' é o que essa cultura particular disse se tratar de um universal. Sempre que se fala em 'universalidade', tem-se um processo de imposição dos valores e das ideias dominantes de uma cultura sobre as demais. Inegavelmente, na construção da categoria jurídica 'direitos humanos' está embutida uma noção de superioridade (espiritual, existencial, política, cultural, bélica etc.) de uma cultura, baseada na crença, acompanhada das melhores intenções (as mesmas que enchem o inferno desde o fenômeno da colonização), de que os seus valores e as suas ideias devem ser transmitidos e incorporados por outras comunidades tidas como inferiores. Tem-se, aqui, mais um exemplo de imposição cultural ao Outro, que muitas vezes se dá mediante o recurso à violência.

Para superar essa violência, típica de uma perspectiva colonizadora, que está na origem do conceito (e do conteúdo hegemônico) de direitos humanos, impõe-se reconstruir esse conceito a partir de uma dialética intercultural, que não exclua o sul global, os povos originários das Américas, as comunidades tradicionais e quilombolas, como mecanismo de interação entre as várias culturas. Reconstruir, aqui, significa uma abertura para diferenças que foram ignoradas na construção eurocentrada do significado atribuído aos direitos humanos. Essa superação dialética terá o potencial de reduzir as assimetrias de poder, compensar as injustiças históricas e socioeconômicas (basta pensar na situação de pobreza gerada pela exploração das ex-colônias, pela escravidão, pelo sucateamento em nome do mercado do Sistema de Saúde etc.) e funcionar como um instrumento de emancipação social.

Para os fins deste breve escrito, por direitos humanos, entende-se o comum, tanto as autorizações para atuar ou não atuar quanto os deveres de agir e de não agir, necessário à realização das potencialidades e da dignidade humana, construído a partir das singularidades, de pessoas que vivem em relação com o outro, que se define a partir do encontro do Eu com o tu, e da superação das linhas ideológica que dividem o Norte do Sul (a 'linha abissal' a que se refere Boaventura de Souza Santos) e o público do privado. Com razão, Herrera Flores ${ }^{\mathbf{7}(14)}$ dizia que

[...] o direito, o pensamento e a prática jurídica comprometida com os direitos humanos de todas e todos podem converter-se na pauta política, ética e social que sirva de guia à construção dessa nova racionalidade, sempre 
e quando os retirarmos da jaula de ferro que os mantém presos na ideologia de mercado e no correlato formalismo jurídico.

Todavia, pode-se também pensar em adotar uma definição puramente formal ou estrutural de direitos humanos: são direitos humanos todos os direitos subjetivos (qualquer expectativa positiva, de uma prestação, ou negativa, de não sofrer lesões, adstrita a uma pessoa) que correspondam a todos e a todas pelo simples fato de serem pessoas. $\mathrm{O}$ importante em uma perspectiva emancipadora, seja diante de um conceito substancial, seja diante de um conceito formal, é que a expressão 'direitos humanos' retrate um instrumento de libertação do indivíduo e de restauração da capacidade de cada pessoa concreta relacionar-se inteiramente com as outras e com a natureza.

Ao lado dos direitos liberais (negativos), chamados de direitos de primeira geração e típicos do Estado de direito liberal, que estabelecem deveres negativos (de não agir), existem direitos sociais que integram o rol dos diretos humanos. Trata-se de direitos vitais e, não raro, também são consagradas nas Constituições como direitos fundamentais. Dentre os direitos humanos de natureza social, típicos do pós-guerra e reflexos da Guerra-Fria (direitos que foram reconhecidos pelos detentores do poder político para tentar reduzir os riscos de uma revolução comunista protagonizada pelos trabalhadores), destacam-se os direitos à alimentação, ao trabalho digno, à habitação, à informação, à educação e à saúde.

Se os direitos de natureza liberal são negativos, e correspondem a vedações ('direitos de'), os direitos de natureza social são positivos, geram expectativas de comportamento alheio ('direitos a') e correspondem a obrigações de agir, deveres públicos de fazer. $\mathrm{O}$ direito à saúde, portanto, enquadra-se entre os direitos humanos de natureza social.

A relação entre direitos humanos e saúde acaba formalizada por intermédio da
Declaração Universal dos Direitos Humanos (1948), que consagrou o direito a uma vida adequada para a saúde e bem-estar. Já nesse momento, a concepção de saúde transcende a mera perspectiva biomédica: não se trata de assegurar tratamentos visando à ausência de doenças ou enfermidades, mas de apontar para uma concepção de direito à saúde que englobe o bem-estar físico, mental e social, ao mesmo tempo que assegure um conjunto de práticas e vivências benéficas à vida das pessoas. Ainda sobre esse conceito ampliado de saúde, há a Declaração de Alma-Ata de 1978, que não só enfatiza a atenção primária à saúde como também relaciona esse direito a diferentes áreas, como a social e a econômica.

O direito à saúde pública de qualidade é assegurado na Constituição da República de 1988, mais precisamente nos arts. $6^{\circ}$ (que o consagra como um dos direitos sociais fundamentais), 193 (que relaciona ordem social ao bem-estar e à justiça social) e 196 (que afirma ser um direito de todos e dever do Estado, garantido mediante políticas sociais e econômicas que visem à redução do risco de doença e de outros agravos e ao acesso universal e igualitário às ações e serviços para sua promoção, proteção e recuperação).

A racionalidade neoliberal, que hoje condiciona o modo de ver e de atuar no mundo, transformou o 'comum' em privado, o ‘direito fundamental' (entendido como limite intransponível ao exercício do poder) em mercadoria, a vida e a dignidade da pessoa humana em objetos negociáveis. Da mesma maneira que o egoísmo foi transformado em virtude, a doença e a crise do sistema de saúde pública passaram a ser vistas como oportunidade para alguns poucos lucrarem e acumularem capital.

O Estado na pós-democracia deixou de ser o promotor e o garantidor dos direitos fundamentais para assumir a função política de regulador das expectativas do mercado e dos detentores do poder econômico. O direito, por sua vez, deixou de ser um regulador social para acabar transformado em mais 
um instrumento para o mercado, ele mesmo transformado em mercadoria; o cidadão, em consumidor. Com isso, a solidariedade, a alteridade e, em consequência, o diálogo são negados, enquanto a diferença e os conflitos capazes de gerar lucros são incentivados.

O Estado pós-democrático enfoca atender ao projeto dos detentores do poder econômico, e isso significa, na área da saúde, induzir medidas que incentivem a saúde privada, os planos de saúde, a terceirização de serviços e o desmonte do Sistema Único de Saúde, tudo como forma de aumentar a produtividade (ou gerar endividamento, o que interessa ao capitalismo financeiro) das empresas que exploram a saúde, estabilizar o mercado (leia-se: proteger os lucros dos detentores do poder político), exercer o controle da qualidade de vida da população e facilitar a acumulação. Essa lógica eficientista, que atende a critérios contábeis e financeiros, na qual a busca de efeitos adequados à razão neoliberal afasta qualquer pretensão do Estado voltar-se à realização dos direitos e garantias fundamentais (efetividade constitucional), em especial do direito à saúde pública de qualidade, acaba incorporada pelos cidadãos e até por operadores do sistema de saúde, não só por questões ideológicas, mas também como fórmula para assegurar vantagens pessoais.

Com o desaparecimento do valor 'saúde', a palavra retorna para nomear algo que não passa de um produto, de uma mercadoria sem forma ou conteúdo estável, sem conexão com projeto constitucional de vida digna para todos. Uma mercadoria oferecida por mercadores especializados, que moldam a 'saúde' ao gosto de critérios de eficiência economicista, mesmo que, para isso, seja necessário suprimir direitos ou prejudicar a qualidade de vida das pessoas.

\section{O que fazer?}

Pode-se afirmar que a passividade da população brasileira diante das restrições, das violações e da falta de efetividade dos direitos fundamentais, entre eles do direito à saúde pública de qualidade, constitui um dado que, provavelmente, foi levado em consideração nas opções políticas (porque o Estado Pós-Democrático resulta de uma opção de natureza política) tomadas em meio às lutas envolvendo agentes e Instituições diversas, a partir de variados interesses materiais e simbólicos, que levaram à pós-democracia.

Mudar esse estado inconstitucional de coisas na área da saúde pública passa necessariamente por um processo de ressimbolização do mundo. É urgente construir um mundo em que a vida digna não seja um privilégio e no qual a saúde de uma pessoa deixe de ser negociada para gerar lucro. É preciso construir uma cultura democrática, comprometida com a realização dos direitos fundamentais de cada pessoa e que imponha limites ao poder, em especial ao poder econômico. 


\section{Referências}

1. Cruch C. Posdemocracia. Madrid: Taurus; 2004.

2. Dardot P, Laval C. A nova razão de mundo. São Paulo: Boitempo; 2016.

3. Santos BS, Chauí M. Direitos humanos, democracia e desenvolvimento. São Paulo: Cortez; 2014.

4. Escrivão Filho A, Souza Junior JG. Para um debate teórico-conceitual e político sobre os direitos humanos. Belo Horizonte: De Plácido, 2016.

5. Baratta Alessandro, organizador. Criminología y sistema penal. D de F: Montevideo; 2014.
6. Casara R. Estado Pós-Democrático: neo-obscurantismo e gestão dos indesejáveis. Rio de Janeiro: Civilização Brasileira; 2017.

7. Herrera Flores J. 16 premisas de una teoría crítica del derecho. In: Proner C, Correas O. Teoría Crítica dos Direitos Humanos. Belo Horizonte: Fórum; 2011, p. 14.

Recebido em 24/08/2018

Aprovado em 10/09/2018

Conflito de interesses: inexistente

Suporte financeiro: não houve 